\title{
Conference conclusions: some overall impressions, themes and questions
}

\author{
Simon Bell ${ }^{1,1}$ \\ ${ }^{1}$ Estonian University of Life Sciences, Chair of Landscape Architecture, Tartu, Estonia
}

\section{Introduction}

During the conference, during each parallel session, as well as during the keynote presentations, one of the co-moderators took some notes of the key aspects to emerge: session highlights, main themes, some key questions raised in discussion and challenges for research in the field. The notes were given to me as the conference chair and from them I summarised some key points for presentation in the final conference session.

\section{Overview of the conference content}

It should be noted that of the 48 papers submitted and presented, four are not included in the proceedings for a variety of reasons and so the abstracts are included instead, along with those of the keynote addresses. Of the presented papers 28 were by researchers on the various MODSCAPES research partner teams and 20 were from other researchers, so there was a $3 / 5$ to $2 / 5$ balance which considering the theme and its relative novelty and, of course, the organisation of the conference being part of the MODSCAPES project, is quite a good balance. This suite of non-MODSCAPES papers broadened out the coverage of the theme in both space and time, with some papers covering more recent modernisation phenomena as well as older versions and also some covering locations well beyond the project territorial borders.

\section{Themes arising from the conference}

The following were the main themes which were drawn out from the sessions as a whole and which reappeared in different guises throughout the conference:

- Housing character and quality

- Land appropriation for colonisation schemes

- Sustainability of the colonisation schemes

- The notion of urban in rural

- The ideological setting of the various programmes

- Infrastructure and the rural landscape

\footnotetext{
${ }^{1}$ Corresponding author: simon.bell@emu.ee
} 
- The new aspects of the agro-business industry

- Tools and methods to capture the spatio-temporal dimension

- Research methods: challenges

- Heritage

Each of these will be considered in turn.

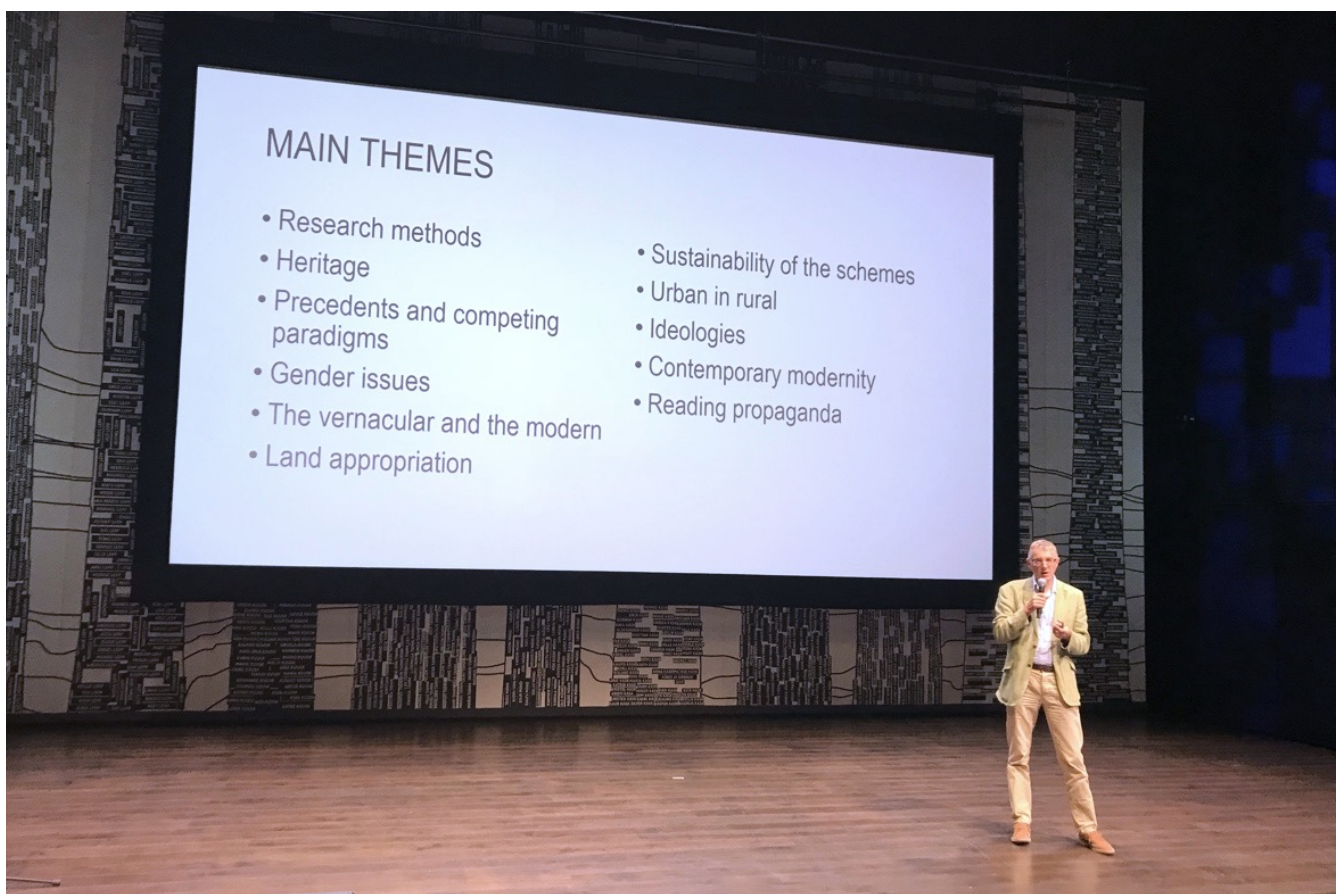

Fig. 1. Prof. Simon Bell presenting the main themes arising from the conference at the ERM Eesti Rahva Museuum - Estonian National Museum's Jakob Hurt hall, 13 June 2018.

(Photo: Josefina González Cubero)

\section{Housing character and quality}

One of the main features of rural colonization and rural improvement has been to provide housing for often rather impoverished areas. Modernism in style has been a feature of many of the examples and under the different political regimes which carried out rural modernization the housing was a focus for introducing new forms of architecture, sometimes with overtly Modernist forms and appearance as well as construction materials (such as the Krushchevka in the Soviet Union) while others incorporated motifs and forms more reminiscent of traditional housing but still firmly within Modernism. One of the features often noted by residents was the inclusion of facilities such as toilets and bathrooms in the houses and flats - and this seemed a sure way to gain support for the new programme as this raised the quality of the living spaces and hygiene standards possibly more than anything else. It also seems that the quality of design mattered more in some places, such as in Italy, while efficient production processes using factory and prefabrication methods was more in important in others, such as the Soviet Union. New models of housing emerged, in some places still keeping the traditional relationship of farmer and animals, such as in Portugal, 
others making a more concerted effort to convert farmers into workers, such as in the Soviet Union.

\section{Land appropriation and colonization schemes}

The means by which land was appropriated for the modernization projects varied quite widely and this emerged as a theme in several papers. It is an important factor as the repercussions continue to this day. Given that many states who practiced the new approaches to rural development were authoritarian or dictatorships at the time, the state had many powers at its disposal. In the Fascist systems, however, landowners and the church maintained a significant role so that appropriation of private land was not as easy as in the Soviet Union where landowners were dispossessed and the state could organize and parcel out land in any way it liked. Overseas colonization such as in Morocco or Libya was another way in which a state could find land and dispossess the indigenous people in favour of colonists. In the years since the systems collapsed or colonies became independent the land may remain in the hands of the settlers - for example in Portugal, Spain or Italy - while the colonists in Morocco and Libya were evicted and the land in Estonia and Latvia were restored to the original owners. This has implications for the landscapes, for the maintenance of drainage systems and the remnant collective buildings which lost their function.

\section{Sustainability of colonisation schemes}

All colonisation schemes were faced with issues of how to maintain themselves as economically and socially viable and, if the settlement is still in existence, how it is maintained today. One factor that emerged was the scale of the scheme and the plot sizes. In the case of schemes where individual farmers were allocated land the viability could depend - and still depends - on the amount needed to support the farmer and his family from a subsistence perspective or economically and in the case of more collective schemes, the territory of the whole agri-business. In addition, the social sustainability depends on attracting and maintaining the active population. With societal and political changes this was both a problem at the time as well as a continuing problem now in many places. Collective farms in Estonia were successively enlarged and only found their viable level almost at the end of the system while in Portugal the plots are too small for viable agriculture nowadays.

\section{The notion of urban in rural}

One key aim running through many schemes was the idea that modernisation could, would or did reduce the differences between urban and rural lifestyles and opportunities. In Estonia the notion of "an urban lifestyle in a rural setting" was a theme also found elsewhere. This in part helped to generate support for the policies as well as to make rural life attractive enough to keep people there and reduce the flow of people to the cities.

\section{The ideological setting of the various programmes}

At the heart of the MODSCAPES project are the ideologies which drove them - ranging from far-right to far-left and everything in between - and the similarities and differences of them as well as the success or failure of the projects and the way they were 
connected via propaganda and many media such as films, posters, publications. It is also clear that the papers which are not associated with the project also tend to have some ideological content, though perhaps not as strongly identified and applied as in many of the project cases.

\section{Infrastructure and the rural landscape}

In many of the reported projects both inside MODSCAPES and from outside, the way in which modernisation resulted in significant infrastructure stands out as a key feature. In most cases these featured extensive drainage works where marshes, swamps and mires were drained using major engineering works in order to bring what was seen as wasteland or unproductive land (as opposed to valuable wetland habitats...) into production. These works were celebrated in the propagandist media and in numerous cases still require to be maintained. One of the challenges raised is the fate of large infrastructure schemes once the land which was in state hands has been subdivided into smaller ownerships or given back to its original owners with no central organisation to maintain the systems. Military infrastructure, road landscapes, mineral extraction and nuclear power stations also featured as parts of the total ensemble of modernist additions to the countryside in several countries.

\section{The new aspects of the agro-business industry}

Looking at the current status of modernisation projects revealed interesting and often surprising ways that the landscapes are now being used and the role of agribusiness in exploiting their qualities. In Italy the Pontine Marshes are now Europe's leading suppliers of kiwi fruits and the farmers are largely Sikhs from India. Recent developments in Belarus were also highlighted. This is part of the continuing story which also needs to be understood, especially in a project which is part of a suite of research funded under the "Uses of the Past" programme.

\section{Tools and methods to capture the spatio-temporal dimension}

Running through many presentations was a methodological theme which focused on the ways in which the spatio-temporal dimensions of the modernist rural landscapes at various scales could be captured, visually represented, and communicated to a wider audience beyond the conventional textual form of the standard academic paper. Once again, in both MODSCAPES and non-MODSCAPES presentation these methodological challenges stood out, offering both novel approaches and challenges.

\section{Research methods: challenges}

A number of issues concerning how to research Modernist rural landscapes emerged in the discussions as follows:

- Adaptation and development of methods and tools: the subject field, being broad and interdisciplinary, requires the careful selection of methods which may involve mixed approaches involving practical and theoretical challenges.

- Connecting the local results with the bigger picture: case studies and examples from different countries pose challenges for making more general conclusions 
and the representativeness as well as the scale differences need to be overcome.

- Combining different representation techniques as coherent research strategy: In multi-disciplinary or multi-method research the ways in which results are presented varies: written narratives, architectural drawing, geographic mapping, historical mapping, document content analysis and social science methods need to be combined so as to present a richer and fuller picture than each is capable of independently.

- How to deal with the quantity, diversity and nature of the materials: The sheer quantity of available materials poses challenges for selection, representativeness, breadth and depth of coverage of the themes and datahandling techniques is very challenging in research in this field.

- How to measure the performance of rural settlements socially or economically as well as politically: what metrics can we use and how can we assess aspects for which there is no data readily available or systems for dealing with paradigms from extinct political systems.

\section{Heritage}

At the core of the MODSCAPES project and in any other work on architecture, landscape and cultural aspects is the concept of heritage. Often, when dealing with landscapes which were under military occupation, the term "dissonant heritage" is widely applied. Key aspects which emerged in the conference were:

- How and by whom is the heritage value of the legacies of modernist rural landscapes decided? This is a key issue since for many people modernist remains are too recent or not interesting enough to be classed as heritage while for others the origins of the elements in the landscape as a result of dictatorships or the reputation of modernist architecture as something unattractive affect the readiness of the public to enter a discourse.

- What does it mean and how is it assessed for different groups of people? As the landscapes under study are in general living and occupied by people working there and who may not be connected to the original projects, the assessment and identification of heritage may have many different meanings.

- What is the ecological value of the nature in such areas and how it is evaluated or protected? A number of examples of projects have had a big impact on ecological values in the past - dams, drainage schemes, mining, intensive agriculture and infrastructure while others following abandonment have gone back to nature and now have ecological values which may cause conflicts when architectural heritage is concerned.

These are key aspects which will be addressed within MODSCAPES as well as emerging in other presentations. 


\section{Precedents and competing paradigms}

Finally, the challenges of a multi-disciplinary project focus on more than integration of methods - they frequently involve completely different paradigms and can be explored using precedents from other projects, such as:

- How to apply or understand the different paradigms of research, planning and scientific domains? This is understandably a challenge for integrated projects and for teams from different countries, universities and disciplines who may not know each other, may come from different countries and totally different research paradigms.

- Through what lenses are we looking and how does this affect the academic discourse and ways of communicating the results of research? This relates to the previous point and also the section on research challenges.

These aspects were raised as needing attention but no solutions were offered in the sessions.

\section{Themes arising from the audience during the final debate}

After presenting the above-mentioned key aspects of the conference reported by comoderators, the audience was given the floor. Some participants added to the following additional key aspects to the discussion.

\section{Community and identity}

The making of modernist rural landscapes appears to be intimately connected to a social group. Hence, the devices and mechanisms through which community was approached, from the planning to the appropriation stage, appear to be a key theme upon which to reflect.

\section{Distinguishing physical features of modernist rural landscapes}

What is it that defines a modernist rural landscape as such, after all? Is it only the planning process, the unique combination of the above-mentioned theme? Is it possible, as one would easily be able to do for many well-characterized and recognizable rural landscapes, to distinguish the objective physical features common of modernist rural landscapes, as opposed to other rural landscapes. Most case-studies presented are situated in flatlands, rather than mountainous areas, although not exclusively: the geographical setting seems to be a possible criteria. Conversely, the physical layout is much more diverse: along with a dominance of grid-like patterns, we find more random patterns, and some "picturesque-like" settings.

\section{Top-down planning, agency and subversion}

Despite being driven by some blueprint, modernist rural landscapes appear to be, on the ground, more complex than being the mere result of top-down policies imposed by some experts or decision-maker upon passive settlers. Several examples showed how competing powers were often at play, and the experts themselves played a role in 
orienting or even subverting the original intentions. Elsewhere, settlers adopted strategies of passive resistance or went on strike, eventually bending the official policies and schemes. Some other cases involved the direct participation of settlers to the implementation and appropriation process, while others had clear democratic and grass-roots mechanisms guiding the devising of policies and schemes. A more shaded picture of who, why and how makes up policies and schemes is likely to shed new and fresh lights on the topic.

\section{Economic cycles and major historical events}

Is the chronological criterion a valid one to compare the different case studies? Many examples emerge as a response to economic and political turmoil, and some major historical events seem to have triggered simultaneous processes in different countries: World War I (and its immediate localized consequences: the collapse of the Ottoman Empire, the Soviet Revolution, the Greek-Turk refugee crisis), the Great Depression, World War II. Other equally important historical events, but of a less global nature, such as civil wars, seem to have had an equally important role in preparing the ground for radical modernization policies of the rural landscape. Hence, not only are all example not fully simultaneous, but their policy-focus seems to escape any possibility of synchronic comparison. A possible hypothesis would be to compare examples according to a diachronic line, where the economic "stage" of development as well as global economic cycle within which it emerges would deserve to be tested.

\section{Conclusions}

The conference succeeded in bringing a diverse range of academics together to discuss an emerging, complex, multi-disciplinary field of research. By exposing the work of the MODSCAPES project out beyond the boundaries of the project teams and by incorporating work by other researchers within the general field a good critical yet productive atmosphere developed. The networking among the participants was made easier by the venue and the relatively modest overall audience which meant there were plenty of opportunities to meet, talk and discuss. The well-moderated sessions also ensured that many aspects were aired which I have been able to bring together in this concluding paper - the aspects which really proceeded from the conference and therefore justify the use of the term "proceedings".

\section{Short Resume}

Simon Bell PhD is Chair professor at the Estonian University of Life Sciences and Associate Director of the OPENspace Research Centre at the University of Edinburgh. He has been president of ECLAS, the European Council of Landscape Architecture Schools between 2012 and 2018. 